\title{
Características da palma forrageira Opuntia spp. com potencial à resistência à cochonilha do carmim Dactylopius opuntiae (Cockerell) (Hemiptera: Dactylopiidae)
}

\section{Érik Serafim da Silva ${ }^{1}, *$, Isaac Araújo Gomes ${ }^{2}$, Luzimar Joventina de Melo', Weverton Pereira de ${ }^{1}$ edeiros ${ }^{2}$ e Marcos Barros de Medeiros ${ }^{1}$}

\footnotetext{
${ }^{1}$ Universidade Federal da Paraíba. Centro de Ciências Humanas, Sociais e Agrárias. Programa de Pós-Graduação em Ciências Agrárias. Rua Pedro de Almeida, 503-541, Bananeiras-PB, Brasil (CEP 58220-000). *E-mail: erik.silva@professor.pb.gov.br.

${ }^{2}$ Universidade Federal do Espírito Santo. Centro de Ciências Exatas. Programa de Pós-Graduação em Química. Av. Fernando Ferrari, 514. Goiabeiras. Vitória-ES, Brasil (CEP 29075-910).

${ }^{3}$ Universidade Federal do Espírito Santo. Centro de Ciências da Saúde. Programa de Pós-Graduação em Biotecnologia. Av. Mal. Campos, 1468. Maruípe. Vitória-ES, Brasil (CEP 29047-105).
}

Resumo. As palmas forrageiras do gênero Opuntia (Cactacea) são originadas do México e consideradas as principais fontes de forragem para rebanhos na Região Nordeste do Brasil. 0 aprimoramento genético aumenta consideravelmente a produção da palma, ampliando sua adaptação, surgindo novos cultivares, corroborando, assim, com os avanços nas pesquisas da palma forrageira nas regiões semiáridas. A alta produtividade, o melhoramento genético da palma também enfrenta o desafio de resistirem à cochonilha do carmim Dactylopius coccus Costa, 1835 (Hemiptera: Dactylopiidae). As principais pragas que atacam as palmas podem ser efetivamente controladas geneticamente. 0 propósito de avaliar os métodos de melhoramento genético, seus resultados e adaptada ao semiárido, essa pesquisa bibliográfica teve como principal objetivo mostrar, com base na literatura pertinente, o potencial de adaptação destas plantas às regiões semiáridas viabilizando um estudo técnico de principais espécies de palma forrageira com potencialidades de resistência à cochonilha do carmim.

Palavras-chave: Melhoramento; Opuntia ficus-indica; Opuntia cochenillifera; Cochonilha do carmim.

Abstract. Characteristics of forage palm Opuntia spp. with potential for resistance to cochineal Dactylopius opuntiae (Cockerell) (Hemiptera: Dactylopiidae). The forage palms of the

Recebido

$02 / 11 / 2020$

Aceito

$06 / 12 / 2020$

Disponível on line

$07 / 12 / 2020$

Publicado

$31 / 12 / 2020$

Acesso aberto

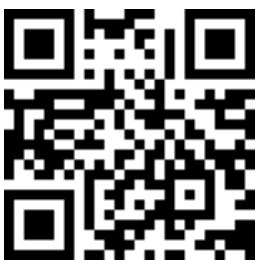

ISSN 2359-1412/RBGAS-2020-0123/2020/7/17/31/1533

Rev. Bras. Gest. Amb. Sustent.

http://revista.ecogestaobrasil.net 
genus Opuntia (Cactacea) originate from Mexico and are considered the main sources of forage for herds in the Northeast Region of Brazil. The genetic improvement considerably increases the production of the palm, expanding its adaptation, emerging new cultivars, corroborating, thus, the advances in the research of forage palm in semiarid regions. High productivity, genetic improvement of the palm also faces the challenge of resisting the scale of the carmine Dactylopius opuntiae (Cockerell) (Hemiptera: Dactylopiidae). The main pests that attack the palms can be effectively controlled genetically. The purpose of evaluating the methods of genetic improvement, their results and adapted to the semiarid, this bibliographic research had as main objective to show, based on the pertinent literature, the potential of adaptation of these plants to the semiarid regions, enabling a technical study of the main species of palm forage with potential for resistance to cochineal.

Keywords: Improvement; Opuntia ficus-indica; Opuntia cochenillifera; Cochineal.

\author{
$\mathrm{ORCID}$ \\ (1) 0000-0002-4224-4113 \\ Érik Serafim da Silva \\ (ㄱ) 0000-0001-7389-0014 \\ Isaac Araújo Gomes \\ (D) 0000-0003-4171-9364 \\ Luzimar Joventina de \\ Melo \\ (D) 0000-0001-9193-894X \\ Weverton Pereira de \\ Medeiros \\ D 0000-0002-1633-3227 \\ Marcos Barros de \\ Medeiros
}

\section{Introdução}

O semiárido é caracterizado pelo clima instável, que limita as atividades agropecuária na Região Nordeste. A concentração de chuvas durante períodos curto ao longo do ano, levando à produção sazonal, redução da oferta de forragem na estação seca e tem um impacto negativo na viabilidade técnica e econômica da produção animal.

O IBGE (2017) apontou aproximadamente 2,3 milhões de estabelecimentos rurais no Semiárido, ocupando 70.643 .037 milhões de hectare, dos quais mais de 455 mil estabelecimentos apresentam área inferior a um hectare. Esses dados apresentados pelo IBGE indicam que mais de um milhão de estabelecimentos são áreas de minifúndios inferior a 10 hectares.

Nesse caso, as palmas forrageiras são plantas ideais, que podem aliviar os efeitos do fraco desempenho do gado em áreas semiáridas. Se manuseada adequadamente, a palma pode alcançar alta produtividade, garantindo os nutrientes necessários aos animais. No entanto, existem variantes genéticas suficientes para explorar em programas de melhoramento para identificar materiais mais adequados. Outro foco da pesquisa da palma forrageira é desenvolver variedades com potencialidade à resistência à cochonilha do carmim, que é sua praga principal.

O Aprimoramento genético aumenta consideravelmente a produção da palma, ampliando sua adaptação, surgindo novos cultivares, corroborando, assim, com os avanços nas pesquisas da palma forrageira nas regiões semiáridas. Além do ganho produtivo, o melhoramento genético possui algo desafiador, desenvolver plantas com potencial a resistência a cochonilha de carmim Dactylopius opuntiae (Cockerell) (Hemiptera: Dactylopiidae). Sendo ela a que mais afeta as palmas, o controle genético pode alterar suas estruturas tornando-a os cultivares resistentes, onde os produtores adotam por não contaminar o espaço e serem de baixo custo de disseminação.

A seleção genética de uma população está fundamentada em genótipos, ambiente e nas interações entre eles dois, o fenótipo. Que dizer, herança genética, características físicas, manejo e condições ambientais, direcionam para uma combinação perfeita destes produtos a resultas positivas. Dentro do contexto relativo ao processo de seleção, o conhecimento dos componentes de variância é de grande importância. Através destes, é 
possível estimar a herdabilidade, predizer o ganho genético e avaliar as potencialidades de uma população, bem como a eficiência relativa dos diferentes métodos de melhoramento, auxiliando, desta forma, a identificar a estratégia de seleção mais adequada.

As regiões semiáridas são as mais vulneráveis às mudanças climáticas, que em consequência do aumento de temperatura e mudanças na precipitação podem tornar-se regiões áridas, provocando alterações não apenas climáticas, mas fitogeográficas, práticas econômicas e sociais (Nóbrega e Santiago, 2016).

Devido às razões da existência e à incerteza do clima, as pesquisas com palmas do tipo forrageiras devem ser fortalecidas em todo o semiárido, buscando novas cultivares e fornecendo aos pecuaristas uma ampla gama de opções de materiais adaptáveis e altamente produtivas. Para isso esse estudo visa correlacionar as características de diversas espécies que vêm sendo desenvolvidas há algumas décadas visando o melhoramento, principalmente porque através da determinação do grau de associação, previsões podem ser feitas tendo em conta a seleção, permitindo dentro do contexto relativo ao processo de seleção, o conhecimento dos componentes de variância que é de fundamental importância. Através destes, é possível estimar a herdabilidade, predizer o ganho genético e avaliar as potencialidades de uma população, bem como a eficiência relativa dos diferentes métodos de melhoramento, auxiliando, desta forma, a identificar a estratégia de seleção mais adequada com potencialidades genéticas resistentes a seca e principalmente a cochonilha do carmim Dactylopius opuntiae (Cockerell) (Hemiptera: Dactylopiidae).

Assim, dada a importância socioeconômica desempenhada pela palma na produção animal em regiões semiáridas, justifica-se o levantamento desta revisão a busca por fontes de variabilidade genética, com vistas ao aumento do potencial produtivo da cultura. A estabilidade e competividade produtiva da palma forrageira depende da utilização dinâmica do germoplasma e da avaliação sistemática de novos genótipos. A definição de estratégias de melhoramento mais eficientes depende, em parte, da descrição precisa dos caracteres de interesse e sua expressão no germoplasma disponível. Além disso, é imprescindível identificar a natureza dessa variação, isto é, se é genética e/ou ambiental. A existência de variabilidade genética é importante para que sejam obtidas novas combinações de maior interesse.

Diante do exposto, essa pesquisa bibliográfica teve como objetivo expor o potencial de adaptação desta planta as regiões semiáridas viabilizando um estudo técnico de principais espécies de palma forrageira (Opuntia spp.) com potencialidades de resistência a cochonilha do carmim Dactylopius opuntiae (Cockerell) (Hemiptera: Dactylopiidae).

\section{Materiais e métodos}

Para a realização da presente pesquisa, foi realizado um levantamento de artigos científicos em bases de periódicos acadêmicos, bases de dados e sites a exemplo do Google Acadêmico e SciELO. A busca foi feita utilizando as seguintes palavras-chave: palma, melhoramento genético, cochonilha, resistência e adaptação. Como critério de inclusão, foram selecionados artigos e matérias publicadas a partir do ano de 2007. Após o agrupamento de dados, as informações mais relevantes a respeito da temática foram discutidas e expostas na presente pesquisa.

\section{Resultados e discussão}

\section{Importância da palma}

Trazida do México no século XIX para o Brasil, sendo cultivado no Nordeste, a palma forrageira devido a sua rusticidade e potencial de produção em baixa precipitação 
pluviométrica tornou-se um relevante recurso para a alimentação animal, principalmente nas regiões semiáridas que são as mais vulneráveis.

Existem cerca de 300 espécies no gênero Opuntia. Sendo amplamente utilizadas na agricultura para produzir frutos e caules comestíveis (usados como alimento para animais), principalmente a Opuntia ficus-indica.

Outras variedades de palmas encontradas na literatura são oriundas da Itália (Ramos et al., 2011), Argélia, Copena-5, Kristalina, Mocha (clones IPASertânea e PALMEPAPQ1) (Gava e Lopes, 2012), palma azu (palma azul), moradella (fórmula), gigantona, língua de vaca e baiana ou alagoana (Lopes et al., 2010). Um destaque especial é a variedade IPA20, obtida através da seleção do programa de melhoramento da IPA após o cruzamento, sendo superior à $\mathrm{cv}$. gigante e de alto rendimento.

A palma destacasse como forrageira ideal, que podem aliviar os efeitos do baixo desempenho em áreas semiáridas na pecuária. Se manuseadas adequadamente, a palma pode alcançar alta produtividade e suplementar os animais (Rocha, 2012).

A palma forrageira (Opuntia spp) pertencente à Família Cactacea é originada do México, considerada uma das principais fontes de forragem para rebanhos na Região Nordeste, apresentando boas características de adaptação ao clima semiárido associada à boa produtividade e alta palatabilidade (Ramos et al., 2017).

Segundo Aguiar et al. (2019) a palma tornou-se a possibilidade mais contundente para a atividade da pecuária bovina no semiárido, ocupando importante papel na alimentação de rebanhos bovinos, sobretudo nos períodos extensos de estiagem representa sobrevivência para os animais e para as famílias criadoras que quase não possuem outras fontes de renda.

\section{Diversidades e características de uso}

Estas cactáceas apresentam propriedades fisiológicas que permitem suportar grandes períodos de escassez de chuva e possui metabolismo fotossintético, designado como metabolismo ácido das crassuláceas (CAM). Há na sua constituição algumas estruturas morfoanatômicas que apresentam adaptações ao ambiente com baixa disponibilidade hídrica, tais como a presença de tricomas e estômatos profundos, no interior de criptas formadas por camadas de cutinas sobre a epiderme (Santos et al., 2010).

Estudo realizado em condições de sequeiro no semiárido brasileiro contemplou as variedades IPA-Sertânia, Miúda e Orelha de Elefante Mexicana. Foram avaliados os indicadores de eficiência do uso da água e de nutrientes. As variedades da palma forrageira Orelha de Elefante Mexicana e a IPA Sertânia se destacaram em relação à eficiência do uso da água considerando a produção de matéria fresca. Todavia, as variedades apresentaram quanto à matéria seca, a mesma eficiência de uso da água, tanto em termos de água precipitada quanto de água evapotranspirada (Silva et al., 2014).

Atualmente, busca-se maximizar a produtividade da planta, através da inserção de técnicas de manejo. Tendo em vista que houve dizimação de aproximadamente 100.000 ha de cultivo da palma Gigante, Opuntia fícus-indica, sendo considerada a variedade tradicional na região semiárida. Visa-se com o aumento da produtividade atender as exigências nutricionais dos animais e minimizar o fornecimento de água, principalmente, em períodos de escassez de chuvas. Contudo, atualmente a palma forrageira tem sido utilizada em período integral durante o ano (Cavalcante e Santos, 2014).

0 cultivo bem sucedido de espécies xerófilas depende principalmente do material genético utilizado, principalmente relacionado a espécies de palmas como a palma (Opuntia spp.), portanto, é necessário realizar programas de melhoramento para selecionar espécies com mais genótipos e com grande potencial de forrageamento (Almeida et al., 2019). 
Atualmente as variedades da palma Orelha de Elefante Mexicana (Opuntia stricta Haw), Miúda (Opuntia cochenillifera (L.) Mill.) e IPA Sertânia (Opuntia sp) vem ganhando destaque no cultivo, entre os agropecuaristas, pois apresentam tolerância à praga da cochonilha do carmim Dactylopius opuntiae (Cockerell) (Hemiptera: Dactylopiidae) que dizimou grandes áreas de cultivos da palma gigante (Opuntia ficus-indica) (Vasconcelos et al., 2009; Lopes et al., 2010).

\section{Melhoramento genético de palmas forrageiras (Opuntia spp)}

0 melhoramento genético de plantas é a arte e a ciência de melhorar os padrões genéticos das plantas com base em seu uso econômico. Seu objetivo é selecionar e desenvolver espécies para novas áreas agrícolas, áreas desfavorecidas e plantas com maior potencial de produção, resistente a pragas e doenças, resistente a condições de estresse abiótico (por exemplo, hídricos e solos salinos) (Fritsche-Neto e Borém, 2011).

Um dos principais cultivares da palmeira forrageira (Opuntia spp.), sendo a planta xerófila mais cultivada no nordeste do Brasil. O programa de melhoramento genético da espécie faz-se necessário para a obtenção de novas variedades com maior potencial produtivo, projetadas para atender às necessidades dos pecuaristas da Região do Semiárido (Almeida et al., 2019).

Na Itália, México, Brasil e Estados Unidos, foram desenvolvidos programas de melhoramento genético da palma. No Brasil, o Instituto de Pesquisa Agropecuária do Estado de Pernambuco (IPA) é uma organização pioneira de pesquisa dedicada à melhoria da palma usada na produção de ração e cultivada BAG na estação experimental de Arcoverde-PE, com 1.417 canais da palma. Produziu 1061 clones de gigantes com polinização descontrolada; 171 clones de pequenas palmeiras com polinização descontrolada; 159 clones da Universidade Chapingo, no México; 17 clones de vários países fornecidos pelo CPATSA; do norte do Rio Cinco clones em Grande; quatro clones introduzidos a partir de Petrolina (Inglese et al., 2017).

A alta produtividade, o melhoramento genético da palma também enfrenta outro desafio, a saber, o desenvolvimento de plantas resistentes à cochonilha de carmim. As principais pragas que atacam as palmas podem ser efetivamente controladas geneticamente. Variedades tolerantes a pragas são fáceis de serem adotadas pelos produtores, não contaminam o meio ambiente e têm baixos custos de produção (Rocha, 2012).

Nas áreas semiáridas, especialmente as com baixa precipitação histórica, a seleção de plantas forrageiras para plantio deve ser baseada na resistência à seca, na fenologia das espécies, características bromatológicas e agronômicas.

Plantas com características fenológicas perenes, ou seja, permanecem verdes o ano todo, principalmente no período mais seco do ano, mesmo no ano com poucas chuvas, torna-se uma opção importante para garantir a produção de forragem e propicia a colheita de plantas em períodos secos, resultando, o baixo apoio à forragem dos produtores rurais é baixa e a forragem é necessária para fornecer os nutrientes necessário para nutri a dieta na ração animal (Almeida et al., 2019).

0 plano de melhoramento genético para espécies vegetais inicialmente, faz-se necessário um bom planejamento, ou seja, primeiro realizar um levantamento bibliográfico de estratégias e programas de melhoramento semelhantes; investigar o germoplasma existente no centro de origem das espécies; verificar o método de reprodução das espécies; determinar o alvo e analisar a implementação do plano obstáculo (Fritsche-Neto e Borém, 2011).

Para estabelecer um plano de melhoramento genético, você deve inicialmente ter um banco de germoplasma ativo (BAG), que é uma coleção viva do patrimônio genético das espécies vegetais, com germoplasma abundante, incluindo material de espécies 
nativas, genótipos crioulos, estirpes e variedades (Costa et al., 2012; Fritsche-Neto e Borém, 2011; Ramos et al., 2007).

\section{Resistência à cochonilha do carmim}

A resistência às pragas e doenças atualmente é uma característica determinante na seleção de uma variedade de palma forrageira (Opuntia spp), nos últimos anos, tem se constatado decréscimo considerável da produção dessa cultura em função do aumento de danos causados por pragas e doenças. A cochonilha do carmim é atualmente a principal praga da cultura na Região Nordeste do Brasil.

A cochonilha do carmim é um inseto que se alimenta das seivas das plantas. Além de sugá-la, ele também introduz vírus e toxinas que deixam as plantas amareladas e com aspectos murcho podendo assim destruir a palma em poucos meses se não for combatida rapidamente. Para identificá-la verifica-se a presença de flocos brancos (colônias) nas raquetes da palma. Ao esmagar as colônias há a liberação de líquido de cor avermelhada.

As plantas exibem uma variedade de estratégias e modificações a fim de reduzir a perda de tecido fotossintético em decorrência do ataque de insetos. As defesas podem ser constitutivas, quando a planta expressa resistência de forma contínua, sem depender da ação de herbívoros, ou induzidas, quando a resistência se expressa somente após a injúria, em alguns minutos, horas ou decorrido um ciclo de cultivo.

As palmas são propagadas através das vias assexuada e sexual, a primeira é a forma mais comum. Sendo vantajoso seu manejo e fácil de multiplicar, sua homogeneidade favorece à propagação de pragas e doenças. Portanto, é necessário identificar métodos de melhoramento genético que visem combatê-los, que garantam a resistência dos cultivares.

$\mathrm{Na}$ atualidade dois cultivares de palmas forrageiras são mais utilizados, a Opuntia fícus-indica Mill. e a Opuntia cochenillifera (L.) Mill., sendo a primeira com características mais rústica e a segunda com maiores exigências em umidade.

Um dos entraves atualmente para essa planta vem sendo a cochonilha do carmim Dactylopius opuntiae (Cockerell) (Hemiptera: Dactylopiidae), a qual se tornou uma praga que está dizimando de forma intensa as plantações de palma, afetando de forma direta e indiretas os produtores que utilizam essa cultura com forrageira, com redução dos rebanhos (Aguiar et al., 2019).

As defesas físicas ou morfológicas, as quais atuam negativamente sobre o inseto, podem ser depósitos cuticulares, epiderme espessada, abundância de cristais, tricomas, fibras na folha. As defesas químicas, que são metabólitos tóxicos e/ou repelentes, atuam minimizando o dano e reduzindo a palatabilidade.

Outras estratégias podem ser usadas no programa de melhoria da cultura, como: introdução de germoplasma; biotecnologia de testes de descendentes (uso de marcadores moleculares, estudos de expressão gênica, cultura de tecidos); indução de mutação para induzir poliploide in vitro; hibridização e outros métodos como culturas estendidas. Uma base genética e um método para obter novos genótipos, que podem ser usados como uma opção para programas de melhoramento genético da cultura (Fritsche e Borém, 2011).

Como a multiplicação in vitro de palma forrageira resistente à cochonilha do carmim vem sendo utilizada no processo de aceleração de produção de mudas, torna-se importante provar se a resistência verificada nos trabalhos de seleção de campo se expressa nas plantas provenientes do cultivo in vitro.

\section{Conclusão}

0 aprimoramento genético da palma forrageira é um caminho árduo que pode durar anos até o lançamento de uma nova cultivar, que seja produtiva, com boas características fisiológicas e com potencial a resistência à cochonilha do carmim. Todavia, é um trabalho importante, pois esses estudos contribuem para dispor ao mercado 
produtos de qualidades que atendam produção animal. A palma pode ser utilizada como uma alternativa forrageira, principalmente em períodos quentes e secos, por ter um papel importante na questão agrícola no cenário futuro do melhoramento.

Nesse cenário de mudança, é essencial a manutenção e o fortalecimento da competência instalada frente ao avanço muito rápido do conhecimento para que o país mantenha um papel protagonista no desenvolvimento científico e tecnológico e na inovação da agricultura. Deve-se, ainda, levar em conta o grande crescimento nas expectativas da sociedade em relação a aspectos como meio ambiente, segurança alimentar, segurança do alimento, entre outros.

Em princípio, o número de melhoristas no Brasil, comparado ao de outros países, principalmente o México, é pequeno, e a maior parte está no IPA, que tem atuado, ao longo do tempo, na produção de novas cultivares. As Universidades Federais, também, possuem número expressivo de melhoristas; contudo, o envolvimento na produção de novas cultivares é reduzido.

Apesar do grande sucesso dos avanços genético vegetal da palma forrageira no país, com mais de um século de capacitação nessa área do conhecimento e resultados que contribuíram, significativamente, para os principais ganhos qualitativos e quantitativos alcançados pela agricultura brasileira ao longo das últimas décadas, alguns eventos vêm modificando o equilíbrio desse segmento de inovação. Entre eles, avanços tecnológicos, provenientes dos avanços da Biotecnologia, tendo em vista o aprimoramento genético dessas culturas xerófilas tornou-se uma ferramenta necessária para o plantio, domesticação de materiais silvestres e aquisição de novas variedades, possui maior potencial de produção e tem a função de aumentar a renda da propriedade rural em áreas semiáridas do Brasil.

Sabe-se que as defesas das plantas ocorrem tanto no tempo quanto no espaço por redes reguladoras altamente complexas que são moduladas por interações com outras vias de sinalização, nas quais as defesas podem ser constitutivas ou induzidas, respondendo rapidamente quando são atacadas novamente. No entanto, ainda não são claros todos os mecanismos envolvidos na interação inseto-planta, bem como estudos que avaliem a pressão de infestação no valor nutritivo de palmas forrageiras, os quais poderiam contribuir para o aprimoramento genético.

Portanto, parte-se da hipótese de que a caracterização molecular e o perfil metabólico permitem identificar os motivos pelos quais alguns genótipos de palma forrageira são mais susceptíveis à cochonilha do carmim do que outros, uma vez que nos estudos histológicos, a espessura da epiderme não é limitante.

Uma das saídas utilizadas frente às pragas e doenças, sem a utilização de agroquímicos, é através do melhoramento genético, selecionando variedades resistentes ou introduzindo genes que codifiquem compostos de resistência sem que haja perdas do valor nutricional, uma vez que esta prática não provoca danos ao meio ambiente. Sendo assim, faz-se necessário aprofundar-se no estudo dos genéticos, morfoanatômomicos, fisiológicos e bioquímicos destas plantas correlacionando com maiores produções e produtividades, tolerância à seca, além de resistência as diversas pragas.

\section{Conflito de interesses}

Os autores declaram não haver conflito de interesses.

\section{Referências}

Aguiar, S. C.; Querino, L. A. L.; Silva, P. F.; Lima, V. L. A. Vulnerabilidade da palma forrageira e pecuária bovina no Estado da Paraíba frente ao ataque da cochonilha do carmim. Revista de Geociências do Nordeste, v. 5, p. 104-115, 2019. 
Almeida, I. V. B.; Souza, J. T. A.; Batista, M. C. Melhoramento genético de plantas forrageiras xerófilas: Revisão. PUBVET, v. 13, n. 7, p. 1-11, 2019. https://doi.org/10.31533/ pubvet.v13n7a382.1-11

Cavalcante, L. A. D.; Santos, G. R. A. Respostas de genótipos de palma forrageira a diferentes densidades de cultivo. Pesquisa Agropecuária Tropical, v. 44, n. 4, p. 424-433, 2014. https://doi.org/10.1590/S1983-40632014000400010

Costa, A. M., Spehar, C. R.; Sereno, J. R. B. Conservação de recursos genéticos no Brasil. Brasília: EMBRAPA, 2012.

Fritsche, N. R.; Borém, A. Melhoramento de plantas para condições de estresses abióticos. Viçosa: Editora UFV, 2011.

Gava, C. A. T.; Lopes, E. B. Produção de mudas de palma forrageira utilizando fragmentos de cladódios. Petrolina: Embrapa Semiárido, 2012. (Instruções Técnicas, 101).

IBGE - Instituto Brasileiro de Geografia e Estatística. Resultados preliminares produção de palma forrageira no Brasil. 2017. Disponível em: <https://censos.ibge.gov.br/agro/2017/ templates/censo_agro/resultadosagro/agricultura.html?localidade=0\&tema $=76582>$.

Acesso em: 06 jun. 2020.

Inglese, P.; Mondragon, C.; Nefzaoui, A.; Saenz, C. Crop ecology, cultivation and uses of cactus pear. Roma: FAO, 2017.

Lopes, E. B.; Brito, C. H.; Albuquerque, I. C.; Batista, J. L. Seleção de genótipos de palma forrageira (Opuntia spp) e (Nopalea spp) resistentes à cochonilha do carmin (Dactylopius opuntiae Cockerele, 1929) na Paraíba, Brasil. Engenharia Ambiental: Pesquisa e Tecnologia, v. 7, n. 1, p. 204-215, 2010.

Nóbrega, R. S.; Santiago, G. A C. F. Tendências do controle climático oceânico sob a variabilidade temporal da precipitação no Nordeste do Brasil. Revista de Geografia Norte Grande, n. 63, p. 9-26, 2016.

Ramos, J. P. F.; Leite, M. L. M. V.; Oliveira Junior, S.; Nascimento, J. P.; Santos, E. M. Crescimento vegetativo de Opuntia ficus-indica em diferentes espaçamentos de plantio. Revista Caatinga, v. 24, n. 3, p. 41-48, 2011.

Ramos, S. R. R., Queiroz, M. A.; Pereira, T. N. S. Recursos genéticos vegetais: manejo e uso. Magistra, v. 19, n. 4, p. 265-273, 2007.

Rocha, J. E. S. Palma forrageira no Nordeste do Brasil: estado da arte. Sobral: Embrapa, 2012.

Santos, M. V. F.; Lira, M. A.; Dubeux Junior, J. C. B.; Guim, A.; Mello, A. C. L.; Cunha, M. V. Potential of Caatinga forage plants in ruminant feeding. Revista Brasileira de Zootecnia, v. 39, p. 204-215, 2010.

Silva, L. M.; Fagundes, J. L.; Viegas, P. A. A.; Muniz, E. N.; Rangel, J. H. A.; Moreira, A. L.; Backes, A. A. Produtividade da palma forrageira cultivada em diferentes densidades de plantio. Ciência Rural, v. 44, n. 11, p. 2064-2071, 2014. https://doi.org/10.1590/01038478cr20131305 
Vasconcelos, A. G. V.; Lira, M. A.; Cavalcanti, V. L. B.; Santos, M. V. F.; Willadino, L. Seleção de clones de palma forrageira resistentes à cochonilha-do-carmim (Dactylopius sp). Revista Brasileira de Zootecnia, v. 38, n. 5, p. 827-831, 2009. https://doi.org/10.1590/S151635982009000500007

Informação da Licença: Este é um artigo Open Access distribuído sob os termos da Licença Creative Commons
Attribution, que permite uso irrestrito, distribuição e reprodução em qualquer meio, desde que a obra original
seja devidamente citada. 